\title{
Cognitive Behavioral Therapy for Somatoform Disorders
}

\author{
Robert L. Woolfolk ${ }^{1,2}$ and Lesley A. Allen ${ }^{2,3}$ \\ ${ }^{1}$ Rutgers University, \\ ${ }^{2}$ Princeton University, \\ ${ }^{3} U M D N J$ - Robert Wood Johnson Medical School, \\ USA
}

\section{Introduction}

Somatoform disorders are characterized by physical symptoms that suggest a medical condition but that are not fully explained by a medical condition. Patients presenting with somatoform disorders represent a formidable challenge to the health care system. These patients tend to overuse health care services, derive little benefit from treatment, and experience protracted impairment, often lasting many years (Smith, Monson, \& Ray, 1986a). Many patients with somatoform symptoms are dissatisfied with the medical services they receive and repeatedly change physicians (Lin et al., 1991). Likewise, physicians of these treatment-resistant patients often feel frustrated by patients' frequent complaints and dissatisfaction with treatment (Hahn, 2001; Lin et al., 1991). Because standard medical care has been relatively unsuccessful in treating somatoform disorders, alternative treatments have been developed. Cognitive-behavioral therapy (CBT) has been the most widely studied alternative treatment for these disorders.

Although medicine has long recognized a group of patients with medically unexplained physical symptoms, excessive health concerns, and abnormal illness behavior, there has been and continues to be disagreement over precise diagnostic labels and criteria. The history of the somatoform disorders begins with hysteria and hypochondriasis. The Egyptians were the first to describe hysteria about 4,000 years ago. Typical cases involved pain in the absence of any injury or pathology in the location of the pain. The Egyptian theory held that a wandering uterus moved about the body and produced pain from various regions (Veith, 1965). The Greeks gave us the word hysteria, from the Greek hystera, meaning womb. Hypochondriasis, also recognized in ancient times, was attributed to disturbances in the upper abdominal organs, such as the spleen and the stomach (Ladee, 1966).

The category of somatoform disorders was not officially recognized until the publication of DSM-III. The original DSM-III category of somatoform disorders included somatization disorder, hypochondriasis, conversion disorder, psychogenic pain disorder, and a residual somatoform disorder category (APA, 1980). The subsequent two editions of DSM included the same disorders with variations in their labels and diagnostic criteria (APA, 1987, 1994). Dysmorphophobia, later named body dysmorphic disorder, was considered a residual 
somatoform disorder in DSM-III and categorized as a distinct disorder in DSM-III-R and DSM-IV (APA, 1980, 1987, 1994). Table 1 outlines the disorders included in each of the editions of DSM.

The chapter provides a review of the diagnostic criteria for the somatoform disorders, according to DSM-IV. Also, summarized is the research on the demographic and clinical characteristics of patients who meet criteria for somatoform disorders as well as the randomized controlled trials examining the efficacy of cognitive behavioral therapy (CBT) for somatoform disorders. Future directions for classification and treatment are also discussed.

\begin{tabular}{|c|c|c|c|}
\hline DSM-III & DSM-III-R & DSM-IV & Proposed DSM-5 \\
\hline Somatization disorder & Somatization disorder & Somatization disorder & \multirow{4}{*}{$\begin{array}{l}\text { Complex somatic } \\
\text { symptom dis } \\
\text { Simple somatic } \\
\text { symptom dis } \\
\text { Illness anxiety } \\
\text { disorder }\end{array}$} \\
\hline Hypochondriasis & Hypochondriasis & Hypochondriasis & \\
\hline \multirow[t]{2}{*}{$\begin{array}{l}\text { Psychogenic pain } \\
\text { disorder }\end{array}$} & $\begin{array}{l}\text { Somatoform pain } \\
\text { disorder }\end{array}$ & Pain disorder & \\
\hline & $\begin{array}{l}\text { Undifferentiated } \\
\text { somatoform disorder }\end{array}$ & $\begin{array}{l}\text { Undifferentiated } \\
\text { somatoform disorder }\end{array}$ & \\
\hline Conversion disorder & Conversion disorder & Conversion disorder & $\begin{array}{l}\text { Neurological } \\
\text { functional disorder }\end{array}$ \\
\hline \multirow[t]{3}{*}{$\begin{array}{l}\text { Atypical somatoform } \\
\text { disorder }\end{array}$} & $\begin{array}{l}\text { Body dysmorphic } \\
\text { disorder }\end{array}$ & $\begin{array}{l}\text { Body dysmorphic } \\
\text { disorder }\end{array}$ & \\
\hline & $\begin{array}{l}\text { Somatoform disorder } \\
\text { NOS }\end{array}$ & $\begin{array}{l}\text { Somatoform disorder } \\
\text { NOS }\end{array}$ & \\
\hline & & & $\begin{array}{l}\text { Psychological factors } \\
\text { affecting medical } \\
\text { condition }\end{array}$ \\
\hline
\end{tabular}

Table 1. Somatoform Disorders 1980 - Present

\section{Somatization disorder and subthreshold somatization}

\subsection{Diagnostic criteria and prevalence}

In DSM-IV somatization disorder is characterized by a lifetime history of at least four unexplained pain complaints (e.g., in the back, chest, joints), two unexplained non-pain gastrointestinal complaints (e.g., nausea, bloating), one unexplained sexual symptom (e.g., sexual dysfunction, irregular menstruation), and one pseudo-neurological symptom (e.g., seizures, paralysis, numbness) (APA, 1994). For a symptom to be counted toward the diagnosis of somatization disorder its presence must be medically unexplained or its degree of severity be substantially in excess of the associated medical pathology. Also, each symptom must either prompt the seeking of medical care or interfere with the patient's functioning. In addition, at least some of the somatization symptoms must have occurred prior to the patient's 30th birthday (APA, 1994). The course of somatization disorder tends to be characterized by symptoms that wax and wane, remitting only to return later and/or be replaced by new unexplained physical symptoms. Thus, somatization disorder is a chronic, polysymptomatic disorder whose requisite symptoms need not be manifested concurrently. 
Epidemiological research suggests that somatization disorder is relatively rare. The prevalence of somatization disorder in the general population has been estimated to be $0.1 \%$ to $0.7 \%$ (Faravelli et al., 1997; Robins \& Reiger, 1991; Weissman, Myers, \& Harding, 1978). When patients in primary care, specialty medical, and psychiatric settings are assessed, the rate of somatization is higher than in the general population, with estimates ranging from $1.0 \%$ to 5.0\% (Altamura et al., 1998; Fabrega, Mezzich, Jacob, \& Ulrich, 1988; Fink, Steen Hansen, \& Søndergaard, 2005; Gureje, Simon, et al., 1997; Kirmayer \& Robbins, 1991; Peveler, Kilkenny, \& Kinmoh, 1997).

Although somatization disorder is classified as a distinct disorder in DSM-IV, it has been argued that somatization disorder represents the extreme end of a somatization continuum (Escobar, Burnam, Karno, Forsythe, \& Golding, 1987; Kroenke, et al., 1997). The number of unexplained physical symptoms reported correlates positively with the patient's degree of emotional distress and functional impairment (Katon, et al., 1991). A broadening of the somatization construct has been advocated by those wishing to underscore the many patients encumbered by unexplained symptoms that are not numerous enough to meet criteria for full somatization disorder (Escobar, et al., 1987; Katon et al., 1991; Kroenke et al., 1997).

DSM-IV includes a residual diagnostic category for subthreshold somatization cases. Undifferentiated somatoform disorder is a diagnosis characterized by one or more medically unexplained physical symptom(s) that are distressing and/or disruptive and that have lasted for at least six months (APA, 1994). Long considered a category that is too broad because it includes patients with only one unexplained symptom as well as those with many unexplained symptoms, undifferentiated somatoform disorder never has been wellvalidated or widely applied (Kroenke, Sharpe, \& Sykes, 2007).

Two research teams have suggested categories for subthreshold somatization using criteria less restrictive and requiring less extensive symptomatology than the standards for DSMIV's full somatization disorder. Escobar and colleagues proposed the label, abridged somatization, to be applied to men experiencing four or more unexplained physical symptoms or to women experiencing six or more unexplained physical symptoms (Escobar, et al., 1987). Kroenke et al. suggested the category of multisomatoform disorder to describe men or women currently experiencing at least three unexplained physical symptoms and reporting a two-year history of somatization (Kroenke et al., 1997).

Both of these subthreshold somatization categories appear to be significantly more prevalent than is somatization disorder as defined by DSM-IV. Abridged somatization has been observed in $4 \%$ of community samples (Escobar, et al., 1987) and $16 \%$ to $22 \%$ of primary care samples (Escobar, Waitzkin, Silver, Gara, \& Holman, 1998; Gureje, Simon et al., 1997; Kirmayer \& Robbins, 1991). The occurrence of multisomatoform disorder has been estimated at $8 \%$ of primary care patients (Jackson \& Kroenke, 2008; Kroenke et al., 1997).

\subsection{Demographic and clinical characteristics}

The demographic characteristic most often associated with somatization is gender. In the Epidemiological Catchment Area (ECA) study, women were 10 times more likely to meet criteria for somatization disorder than were men (Swartz, Landermann, George, Blazer, \& Escobar, 1991). Higher rates of occurrence in women, though not as extreme, also have been 
found in most studies employing subthreshold somatization categories, such as Escobar's abridged somatization or Kroenke's multisomatoform disorder (Escobar, Rubio-Stipec, Canino, \& Karno, 1989; Kroenke et al., 1997). A more complex picture of the association between gender and somatization was suggested by the WHO's Cross-National study in which female primary care patients were more likely to meet criteria for full somatization disorder, but no more likely to meet Escobar's abridged somatization criteria than were their male counterparts (Gureje, Simon, et al., 1997). On the severe end of the continuum, somatization disorder is uncommon in men. Gender differences are less obvious in the various subthreshold syndromes.

Ethnicity, race, and education have been associated with somatization disorder and subthreshold somatization. Epidemiological research has shown somatization patients more likely to be non-white and less educated than non-somatizers (Gureje, Simon, et al., 1997; Robins \& Reiger, 1991). Findings on ethnicity have been less consistent across studies. In the ECA study, Hispanics were no more likely to meet criteria for somatization disorder than were non-Hispanics (Robins \& Reiger, 1991). The WHO study, conducted in 14 different countries, revealed a higher incidence of somatization, as defined by either ICD-10 or Escobar's abridged criteria, in Latin American countries than in the United States (Gureje, Simon, et al., 1997).

Much attention has focused on somatization patients' illness behavior and the resulting impact of that behavior on the health care system. These patients disproportionately use and misuse health care services. When standard diagnostic evaluations fail to uncover organic pathology, somatization patients tend to seek additional medical procedures, often from several different physicians. Patients may even subject themselves to unnecessary hospitalizations and surgeries, which introduce the risk of iatrogenic illness (Fink, 1992). One study found that somatization disorder patients, on average, incurred nine times the US per capita health care cost (Smith et al., 1986a). Abridged somatization and multisomatoform disorder also have been associated with significant health care utilization (Barsky, Orav, \& Bates, 2005; Escobar, Golding, Hough, Karno, Burnam, \& Wells, 1987; Kroenke et al., 1997).

The abnormal illness behavior of somatizing patients extends beyond medical offices and hospitals to patients' workplaces and households. Somatizers withdraw from both productive and pleasurable activities because of discomfort, fatigue, and/or fears of exacerbating their symptoms. In a study assessing the efficacy of cognitive behavior therapy for somatization disorder, we found $19 \%$ of patients meeting DSM-IV criteria for somatization disorder to be receiving disability payments from either their employers or the government (Allen, Woolfolk, Escobar, Gara, \& Hamer, 2006). Estimates of unemployment among somatization disorder patients range from 36\% to 83\% (Allen et al., 2006; Smith et al., 1986a; Yutzy et al., 1995). Whether working outside their homes or not, these patients report substantial functional impairment. Some investigators have found that somatization disorder patients report being bedridden for 2 to 7 days per month (Katon et al., 1991; Smith et al., 1986a). Likewise, high levels of functional impairment have been associated with subthreshold somatization (Allen, Gara, Escobar, Waitzkin, Cohen-Silver, 2001; Escobar, Golding, et al., 1987; Gureje, Simon, et al., 1997; Jackson \& Kroenke, 2008; Kroenke et al., 1997). 
In addition to their physical complaints, many somatization patients complain of psychiatric distress. As many as $80 \%$ of patients meeting criteria for somatization disorder or subthreshold somatization meet DSM criteria for another lifetime Axis I disorder, usually an anxiety or mood disorder (Smith et al., 1986a; Swartz, Blazer, George, \& Landerman, 1986). When investigators consider only current psychiatric diagnoses, rates of Axis I psychiatric co-morbidity associated with somatization are closer to 50\% (Allen, Gara, Escobar, Waitzkin, Cohen-Silver, 2001; Simon \& Von Korff, 1991). Rates of Axis II psychiatric co-morbidity also are high (Garcia-Campayo, Alda, Sobradiel, Olivan, \& Pascual, 2007; Rost, Akins, Brown, \& Smith, 1992). Also, overall severity of psychological distress, defined as the number of psychological symptoms reported, correlates positively with the number of functional somatic symptoms reported (Katon et al., 1991; Simon \& Von Korff, 1991).

\subsection{Cognitive behavioral treatment}

A number of studies have been conducted examining the efficacy of cognitive behavioral therapy (CBT) for somatization disorder or for subthreshold somatization. Two studies enrolled patients with at least one somatization symptom. Two other studies enrolled patients with multiple medically unexplained symptoms. Only study one enrolled patients meeting DSM-IV criteria for somatization disorder, the most severely disturbed somatizating patients. Various different approaches to integrating CBT into primary care have also been investigated.

The earliest randomized controlled trials on CBT for somatization included patients presenting with relatively mild levels of somatization, patients presenting with at least one psychosomatic symptom. The treatment protocols included identifying and restructuring dysfunctional cognitions, behavioral activation or reengaging patients in avoided activities, problem-solving, and relaxation training (Lidbeck, 1997; Speckens et al., 1995). In the first study patients treated with 6 to 16 sessions of individually-administered CBT showed significantly greater improvement in their psychosomatic complaints than did patients treated with standard medical care (Speckens et al., 1995). The other study found an 8session group CBT superior to a waiting-list control condition in reducing physical symptoms and hypochondriacal beliefs (Lidbeck, 1997). In both studies improvements were observed after treatment as well as six months later (Lidbeck, 1997; Speckens et al., 1995). Both of these studies were conducted in primary care offices, the setting where somatization is most likely to be seen.

Two more recently published randomized controlled trials examined the efficacy of CBT for somatization with patients presenting with more severe somatization than the earlier trials. One study required participants meet Escobar's criteria of abridged somatization. That is, men were required to experience at least four somatization symptoms and women were required to experience at least six somatization symptoms (Escobar et al., 2007). The other trial enrolled participants who complained of five or more unexplained physical symptoms (Sumathipala, Hewege, Hanwella, \& Mann, 2000). In both studies patients were identified and treated with CBT in primary care. Treatment protocols were similar to that of Lidbeck (1997) and Speckens et al., (1995) with the addition of involving the patient's spouse or other family member in treatment (Escobar et al., 2007; Sumathipala et al., 2000). Findings from both trials show individual CBT coincided with greater reductions in somatic complaints than did standard medical care (Escobar et al., 2007; Sumathipala et al., 2000). CBT was 
associated with a reduction in the number of physician visits in one study (Sumathipala et al., 2000).

We are the only group of researchers who have published a randomized controlled trial on the efficacy of CBT for full somatization disorder (Allen, Woolfolk, Escobar, Gara, \& Hamer, 2006). In the study 84 patients meeting DSM-IV criteria for somatization disorder were randomly assigned to one of two conditions: (1) standard medical care or (2) a 10-session manualized individually-administered CBT in combination with standard medical care. The treatment protocol included relaxation training, activity regulation, facilitation of emotional awareness, cognitive restructuring, and interpersonal communication. Although the elicitation and exploration of affect is an approach rarely used in CBT, we have found this component to be a powerful clinical tool with patients who cannot or do not willingly access and experience emotion. We have described our treatment in detail elsewhere (Woolfolk \& Allen, 2007). Participants' symptomatology and functioning were assessed with clinicianadministered instruments, self-report questionnaires, and medical records before randomization as well as 3 months, 9 months, and 15 months after randomization. Just after the completion of treatment as well as one year later, i.e., at the 15-month follow-up assessment, patients who received CBT experienced a greater reduction in somatization and functional impairment. Substantially more participants who received CBT than the control treatment were rated as either "very much improved" or "much improved" by a clinician who was blind to participants' treatment condition ( $40 \%$ vs. $5 \%$, respectively). Also, for the $68 \%$ of the sample for whom complete medical records were reviewed, CBT was associated with a reduction in health care costs and physician visits (Allen et al., 2006). Thus, the study suggests CBT can result in long-term improvements in the symptomatology, functioning, and health care utilization of the most severely disturbed somatizing patients.

\subsection{Integrating CBT into primary care}

Because somatization is so prevalent in primary care practices (Escobar, Waitzkin et al., 1998; Gureje, Simon et al., 1997; Kirmayer \& Robbins, 1991), other approaches to the treatment of somatization have been focused on primary care physicians' behavior. Smith and colleagues sent a psychiatric consultation letter to patients' primary care physicians, describing somatization disorder and providing recommendations to guide primary care (Smith, Monson, \& Ray, 1986b). The recommendations to physicians were straightforward: (a) to schedule somatizers' appointments every 4 to 6 weeks instead of "as needed", (b) to conduct a physical examination in the organ system or body part relevant to the presenting complaint, (c) to avoid diagnostic procedures and surgeries unless clearly indicated by underlying somatic pathology, and (d) to avoid making disparaging statements, such as "your symptoms are all in your head." Patients whose primary physicians had received the consultation letter experienced better health outcomes, such as physical functioning and cost of medical care, than those whose physicians had not received the letter. The results were replicated in three additional studies, one study using patients meeting criteria for full somatization disorder (Rost, Kashner, \& Smith, 1994) and two studies using patients with subthreshold somatization (Dickinson, et al., 2003; Smith, Rost, \& Kashner, 1995).

Given the success of the above-described consultation letter and the success of CBT, some investigators have attempted to train primary care physicians to better detect somatization 
and to incorporate cognitive and behavioral techniques into their treatment of these patients. Five groups of investigators have reported controlled clinical trials on the effects of such physician training (Arnold et al., 2009; Larish, Schweickhardt, Wirsching, \& Fritzsche, 2004; Morriss et al., 2007; Rief, Martin, Rauh, Zech, \& Bender, 2006; Rosendal et al., 2007). The two studies providing the most extensive physician training (20-25 hours) resulted in no association between physician training and patients' symptomatology, functioning, or quality of life (Arnold et al., 2009; Rosendal et al., 2007). Three other studies found less intensive physician training programs, 12 hours (Larish et al., 2004) or 1 day (Rief et al., 2006) or six hours (Morriss et al., 2007) to coincide with no clear improvement in somatization symptomatology; however, Rief and colleagues did find their training to coincide with fewer health care visits for the 6 months subsequent to training (Rief et al., 2006).

One other study examined the effect of training primary care clinicians to identify and treat somatization using a biopsychosocial model (Smith et al., 2006). This study involved the most intensive such training programs studied, one entailing 84 hours over 10 weeks. Nurse practitioners were trained to provide a year-long 12-session multidimensional intervention in primary care that incorporated biopsychosocial conceptualizations of, behavioral recommendations for, and medication management of somatization. Patients who received treatment from these trained nurses reported modest improvements on self-report scales of mental health such as mood and energy and physical functioning. A post hoc analysis was interpreted by the study's investigators as suggesting improvements were attributable to more frequent and appropriate use of antidepressant medication among patients of nurses who received the training (Smith et al., 2006).

A slightly different model for integrating CBT into primary care is a collaborative care model of treatment, in which mental health professionals work together with medical practitioners in the primary care setting (Katon et al., 1995; von Korff, Gruman, Schaefer, Curry \& Wagner, 1997). The one study investigating the efficacy of such a model for the treatment of somatization had psychiatrists provide primary care physicians and their staff with training on the diagnosis and treatment of somatization and comorbid psychopathology (van der Feltz-Cornelis, van Oppen, Ader, \& van Dyck, 2006). Also, the psychiatrist provided case-specific consultations to primary physicians regarding referrals for CBT and/or psychiatric treatment (van der Feltz-Cornelis et al., 2006). A control comparison treatment included the same training for primary care physicians and their staff by the psychiatrist without the case-specific consultation. Six months after randomization, participants whose primary care physician received psychiatric consultation reported a greater reduction in somatic symptoms and in health care visits (van der Feltz-Cornelis et al., 2006).

In all, the literature on the treatment of somatization supports the use of 6-16 sessions of CBT administered by a mental health professional. A recent meta-analysis indicated CBT is modestly effective in reducing somatization symptomatology and minimally effective improving physical functioning (Kleinstäuber, Witthöft, \& Hiller, 2011). To date there is no evidence that CBT reduces health care services when the cost of CBT itself is considered. Researchers have just begun to develop and examine the effectiveness of true collaboration between cognitive behavioral therapists and primary care clinicians and integration of their services. 


\section{Hypochondriasis}

\subsection{Diagnostic criteria and prevalence}

According to DSM-IV, hypochondriasis is defined as a "preoccupation with fears of having, or the idea that one has, a serious disease based on the person's misinterpretation of bodily symptoms" (APA, 1994, p. 462). This preoccupation must last for at least six months, persist despite medical evaluation and physician reassurance, and cause significant distress or impairment in one's functioning (APA, 1994). Thus, unlike in somatization where the distress and dysfunction experienced is due to the physical symptoms themselves, in hypochondriasis the distress and dysfunction is due to the patient's interpretation of the meaning of his or her symptoms. The course of hypochondriasis is often chronic: As many as $50 \%$ of patients meeting DSM criteria for hypochondriasis have excessive health concerns for many years (Barsky, Fama, Bailey \& Ahern, 1998; Barsky, Wyshak, Klerman, \& Latham, 1990).

There are only a few epidemiological studies that have examined the prevalence of hypochondriasis. Studies that have utilized a clinical interview to assess prevalence have suggested that hypochondriasis occurs rarely in the general population. Such estimates range from 0.02 to 1.6\% (Faravelli et al., 1997; Looper \& Kirmayer, 2001; Martin \& Jacobi, 2006). In primary care, estimates range from $0.8 \%$ to $6.3 \%$ (Barsky et al., 1990; Escobar, Gara, et al. 1998; Gureje, Ustun, \& Simon, 1997).

\subsection{Demographic and clinical characteristics}

Unlike somatization disorder, hypochondriasis does not appear to be related to gender (Barsky et al, 1990; Gureje, et al., 1997; Looper \& Kirmayer, 2001). Men are as likely to meet DSM criteria for hypochondriasis as are women. Findings have been inconsistent on whether hypochondriasis is related to education, socio-economic status, and ethnicity (Barsky et al., 1990; Gureje, et al., 1997).

Like patients with somatization disorder and milder versions of somatization disorder, those with hypochondriasis exhibit abnormal illness behavior. They over-utilize health care (Gureje, Ustun, et al., 1997; Looper \& Kirmayer, 2001), subjecting themselves to multiple physician visits and multiple diagnostic procedures. They report great dissatisfaction with their medical care (Barksy, 1996; Noyes et al., 1993). In addition, patients diagnosed with hypochondriasis report substantial physical impairment and functional limitations related to employment (Escobar et al., 1998; Gureje, Ustun, et al., 1997; Looper \& Kirmayer, 2001; Noyes et al., 1993). Also, hypochondriasis frequently co-occurs with other Axis I disorders, such as mood, anxiety, or other somatoform disorders (Gureje, Ustun, et al., 1997; Noyes et al., 1994) and various Axis II disorders (Sakai, Nestoriuc, Nolido, \& Barsky, 2010).

\subsection{Cognitive behavioral treatment}

Psychosocial treatments for hypochondriasis have been examined in six randomized controlled trials. The interventions in all six studies were brief (i.e., 6 to 16 sessions), theoretically grounded in social learning theory, and administered on an individual basis. Three groups of investigators examined the efficacy of CBT (Barsky \& Ahern, 2004; Greeven et al., 2007; Warwick, Clark, Cobb, \& Salkovskis, 1996). Two other trials 
examined the efficacy of treatments, labeled cognitive therapy (CT) (Clark et al., 1998; Visser \& Bouman, 2001). Behavioral stress management, exposure in vivo plus response prevention, and explanatory therapy have also been studied, each in one randomized controlled trial. Below we provide an elaboration of the specific interventions and a review of the studies' findings.

All treatments labeled CBT or CT involved identifying and challenging patients' misinterpretations of physical symptoms as well as constructing more realistic interpretations of them (Barsky \& Ahern, 2004; Clark et al., 1998; Greeven et al., 2007; Visser \& Bouman, 2001; Warwick, Clark, Cobb, \& Salkovskis, 1996). Visser and Bouman's (2001) CT consisted of a "pure CT" that focused on only cognitive elements of treatment. Clark et al.'s CT (1998), on the other hand appears to be procedurally similar to the point of being indistinguishable from many of those labeled CBT for hypochondriasis (Greeven et al., 2007; Warwick, Clark, Cobb, \& Salkovskis, 1996). Specifically, most CBT and Clark et al.'s CT combined cognitive restructuring with exposure to interoceptive and/or external stimuli along with response prevention after exposure (Clark et al., 1998; Greeven et al., 2007; Warwick et al., 1996). Barsky and Ahern's CBT did not include exposure plus response prevention. Instead, they attempted to reduce patients' tendency to amplify physical symptoms and to alter patients' illness behaviors, in addition to restructuring cognitions (Barsky \& Ahern, 2004). Another difference among the treatments was their durations. Barsky and Ahern's (2004) treatment entailed six 90-min sessions. Visser and Bouman's (2001) intervention consisted of 12 weekly sessions, each presumably lasting 1 hour, though session duration was not indicated. The duration of Greeven et al.'s (2007) CBT which was "based on the treatment protocol used by Visser and Bouman," (p. 93) ranged from 6 to 16 sessions. Both Clark et al.'s (1998) and Warwick et al.'s (1996) treatments involved 16 1-hour sessions.

All CT and CBT interventions were associated with significantly greater reductions in hypochondriacal symptoms than was the comparable waiting list or standard medical care control condition (Barsky \& Ahern, 2004; Clark et al., 1998; Greeven et al., 2007; Visser \& Bouman, 2001; Warwick, et al., 1996). Barsky and Ahern's study was the only one that examined long-term differences between the control group and the treated group: Ten months after treatment completion, patients enrolled in CBT reported a greater decline in hypochondriacal cognitions than did controls. Also, Barsky and Ahren's CBT-treated participants reported a significantly greater increase in daily activities than did controls, even 10 months after treatment (Barsky \& Ahern, 2004).

In addition to their pure CT condition, Visser and Bouman (2001) also assessed the efficacy of a largely behavioral intervention, exposure plus response prevention. Patients receiving this treatment constructed hierarchies of their own hypochondriacal fears and avoidance behavior patterns, such as checking, reassurance seeking, avoidance of interoceptive and/or external stimuli. Afterwards, they were given assignments of in vivo exposure and response prevention. Patients treated with exposure reported significantly greater reductions in their hypochondriacal symptoms than did wait-list control participants. Although Visser and Bouman also compared exposure plus response prevention to their CT intervention described above, the study was not sufficiently powerful to distinguish between the two treatments. 
Clark et al. (1998) created a psychosocial alternative to CT, behavioral stress management (BSM) that did not directly address hypochondriacal concerns. It was intended to address anxiety related to hypochondriasis by training patients in relaxation, problem-solving, assertiveness training, and time management. Clark et al. (1998) found behavioral stress management significantly more effective in alleviating hypochondriacal concerns than was a waiting list. Clark et al. also compared this treatment to their CT described earlier. At post-treatment CT-treated participants experienced greater reductions in their hypochondrical cognitions than did BSM-treated participants. Nevertheless, 12 months after the post-treatment assessment, these differences were not observed (Clark et al., 1998).

Finally, Fava et al. examined the efficacy of explanatory therapy (Kellner, 1983) for hypochondriasis, in hopes of identifying a beneficial treatment that is less complex and easier to administer than CBT (Fava, Grandi, Rafanelli, Fabbri, \& Cazzaro, 2000). Explanatory therapy is a physician-administered individual therapy consisting of patient education, reassurance, and training in selective attention (i.e., reducing somatic attention). Like the cognitive and behavioral treatments described above, explanatory therapy resulted in greater reductions in worry about illness than did the waiting list (Fava et al., 2000). Although explanatory therapy was also associated with greater reductions in physician visits than was the control group, the mean reduction in visits was minimal (3 visits) considering the treatment group received 8 additional visits as part of their explanatory therapy (Fava et al., 2000).

The one study comparing a psychosocial intervention with a pharmacological intervention demonstrated that CBT was more effective than a placebo pill, but no more effective than paroxetine, in reducing hypochondriacal beliefs (Greeven et al., 2007). Despite the statistical significance of these findings, the clinical significance of changes observed in this study suggests that patients experienced only modest improvement. Instead of using Jacobson's recommendation of a change of 1.96 standard deviations from the pretreatment mean as an index of clinically significant change, the investigators judged as clinically significant a change of 1.0 standard deviation. Using this more lenient criterion, only $45 \%$ of CBT recipients and $30 \%$ of paroxetine recipients versus $14 \%$ of waiting list controls responded to treatment at clinically significant levels (Greeven et al. 2007).

\subsection{Integrating CBT into primary care}

Given the prevalence of hypochondriasis in medical practices (Barsky et al., 1990; Escobar, Gara, et al., 1998; Gureje, Ustun, et al., 1997), it would seem important to develop treatments to be administered in medical settings. Only one of the randomized controlled trials described above was conducted in primary care (Barsky \& Ahern, 2004). All other trials were conducted in mental health or psychosomatic medicine clinics, and thus leave open to question the generalizability of findings to hypochondriacal primary care patients. Will primary care patients with concerns about their physical health be open to a treatment designed to challenge the validity of those concerns? A significant proportion (29\%) of the patients recruited for Barsky and Ahern's study declined to participate (Barsky \& Ahern, 2004). Future research could examine the efficacy of CBT that is integrated and coordinated with primary care. 


\section{Conversion disorder}

\subsection{Diagnostic criteria and prevalence}

Conversion symptoms, also described as pseudo-neurological symptoms, are abnormalities or deficits in voluntary motor or sensory function that are medically unexplained. Some of the most common pseudo-neurological symptoms are pseudo-seizures, pseudo-paralysis and psychogenic movement disorders. According to DSM-IV, conversion disorder is characterized by the presence of one or more pseudo-neurological symptoms that are distressing and/or disruptive and are associated with psychological stressor(s) or conflict(s). Also, the symptoms can not be intentionally produced or feigned (APA, 1994). The diagnosis of conversion disorder requires a thorough psychiatric evaluation as well as a physical examination in order to rule out organic neurological illness. Patients presenting with conversion symptoms typically have normal reflexes and normal muscle tone.

The course of conversion disorder appears to be different from that of somatization disorder, which tends to be chronic (Kent, Tomasson, \& Coryell, 1995). The onset and course of conversion disorder often take the form of an acute episode. Symptoms may remit within a few weeks of an initial episode and they may recur in the future. Some research indicates that a brief duration of symptoms prior to treatment is associated a better prognosis (Crimlisk et al., 1998; Hafeiz, 1980; Ron, 2001).

Estimates of the prevalence of conversion disorder have varied widely, ranging from 0.01 to $0.3 \%$ in the community (Faravelli et al., 1997; Stefansson, Messina, \& Meyerowitz, 1979). As is the case with the other somatoform disorders, conversion disorder is much more common in medical and psychiatric practices than in community samples. As many as $25 \%$ of neurology clinic patients may present for treatment of a medically unexplained neurological symptom (Creed, Firth, Timol, Metcalf \& Pollock, 1990; Perkin, 1989).

\subsection{Demographic and clinical characteristics}

The demographic characteristics of conversion disorder have not been investigated extensively. Nevertheless, there is some evidence that conversion disorder is more common among women (Deveci et al., 2007; Faravelli et al., 1997), non-whites (Stefansson, et al., 1979), and individuals from lower socioeconomic classes (Folks, Ford, \& Regan, 1984; Stefansson, et al., 1979). Co-morbid psychiatric distress in patients with pseudo-neurological symptoms is high; it has been estimated that $30 \%$ to $90 \%$ of patients seeking treatment for pseudo-neurological symptoms also meet criteria for at least one other psychiatric disorder, typically somatoform disorders, affective disorders, anxiety disorders, or personality disorders (Binzer, Andersen, \& Kullgren, 1997; Crimlisk et al., 1998; Mokleby, Akyuz, Kundakel, Kizitlan \& Dogan, 2002; Sar et al., 2004). A co-morbid personality disorder diagnosis has been found to indicate poor prognosis of conversion disorder (Mace \& Trimble, 1996).

Like somatization disorder, conversion disorder is costly to the health care system, especially when symptoms are chronic (Mace \& Trimble, 1996). Patients with long-standing conversion symptoms are likely to submit themselves to unnecessary diagnostic and medical procedures. Martin and colleagues reported an average of $\$ 100,000$ being spent per year per conversion disorder patient (Martin, Bell, Hermann, \& Mennemeyer, 2003). 


\subsection{Cognitive behavioral treatment}

We are aware of only one published randomized controlled trial investigating the efficacy of CBT for conversion disorder. In the study patients diagnosed by a neurologist as having psychogenic nonepileptic seizures were randomly assigned to receive standard neuropsychiatry care alone or standard neuropsychiatry care plus individual CBT (Goldstein et al., 2010). The 12-session CBT was designed to help patients interrupt behavioral, physiological, and emotional responses that occurred at the onset of seizures. Specifically, patients were encouraged to engage in avoided activities, utilize relaxation methods, and restructure their dysfunctional cognitions (Goldstein et al., 2010). At the conclusion of treatment, patients who received CBT reported a greater reduction in psychogenic seizures than did the control group. At the 6-month follow up assessment, the difference between treatment and control groups was only marginally significant. Health care utilization and social and work functioning did not change differentially between the treatment groups (Goldstein et al., 2010).

\section{Pain disorder}

\subsection{Diagnostic criteria and prevalence}

Pain disorder is characterized by clinically significant pain that is judged to be affected by psychological factors (APA, 1994). Very little research has been conducted that addresses pain disorder as defined by DSM-IV (or its counterparts, psychogenic pain disorder and somatoform pain disorder in DSM-III and DSM-III-R, respectively) as a discrete diagnostic category. Instead, researchers have tended to formulate research based on the anatomical site and the chronicity of the pain. Thus, there is a voluminous literature on distinct pain conditions, e.g., back pain, chest pain, pelvic pain, headaches. In very few of these studies have investigators attempted to distinguish between pain that was apparently affected by psychological factors and pain that was apparently not, presumably because such a distinction is too difficult to make and perhaps unreliable.

The few investigators who have examined the epidemiology of somatoform pain disorder, instead of specific pain syndromes, have not assessed whether psychological factors were involved in the onset, severity, exacerbation, or maintenance of the pain, as required by DSM-IV. Instead, the diagnosis was made for medically unexplained pain that lasted six months and impaired functioning. In these studies, somatoform pain disorder had a oneyear prevalence of $0.6 \%$ to $8.1 \%$ (Faravelli et al., 1997; Frohlich, Jacobi, \& Wittchen, 2005) and a lifetime prevalence of $12.3 \%$ (Grabe et al., 2003).

Given the difficulty of determining whether psychological factors are associated pain symptoms and the similarity of the presentation of pain disorder with that of somatization disorder and subthreshold somatization, many experts have suggested the elimination of the pain disorder category from future versions of DSM (Birket-Smith \& Mortenson, 2002; Kroenke, et al., 2007; Sullivan, 2000). In fact, the most recent proposal for DSM-5 has eliminated this diagnostic label (APA, 2010).

\subsection{Demographic and clinical characteristics}

The limited body of research on pain disorder suggests that it is associated with functional impairment, overuse of medical services, and psychopathology (Frohlich et al., 2005). 


\subsection{Cognitive behavioral treatment}

We are not aware of any published randomized controlled trial investigating the efficacy of CBT for DSM-IV pain disorder or for the DSM-III or DSM-III-R counterparts to it. Reviews on CBT for specific pain disorders, such as non-cardiac chest pain, chronic back pain, headaches, can be found elsewhere and are consistent with the findings for other somatoform disorders showing CBT to be associated with modest benefits in symptomatology (Kisely, Campbell, Skerritt, \& Yelland, 2010; Kröner-Herwig, 2009).

\section{Body dysmorphic disorder}

\subsection{Diagnostic criteria and prevalence}

DSM-IV body dysmorphic disorder (BDD) is characterized by a preoccupation with an imagined defect in appearance. If a slight physical irregularity is present, the person's concern must be excessive to be meet criteria for BDD. Also required for a diagnosis of BDD is significant distress or impairment caused by this preoccupation (APA, 1994). Typically, patients are concerned about their skin or complexion, the size of the nose or head, or the attractiveness of the hair; however, the preoccupation may concern any body part.

BDD tends to be chronic. In one study Phillips at al. found only a 0.09 probability of full remission and 0.21 probably of partial remission over the course of a year (Phillips, Pagano, Menard, \& Stout, 2006).

The prevalence of BDD is uncertain. Research conducted in community settings has produced varying estimates: a prevalence of $0.7 \%$ in a community setting in Italy (Faravelli et al., 1997), 1.7 \% in a national survey of German adolescents and adults (Reif, Buhlmann, Wilhelm, Borkenhagen, \& Brähler, 2006), and 2.4\% in a telephone survey of U.S. adults (Koran, Abujaoude, Large, \& Serpe, 2008). The prevalence of BDD in medical practices has been found to be substantially higher than that found in the general population: $4 \%$ of general medicine patients (Phillips, 1996), 3\% to $16 \%$ of cosmetic surgery patients (Sarwer \& Crerand, 2008), and $8 \%$ to $15 \%$ of dermatology patients (Sarwer \& Crerand, 2008).

\subsection{Demographic and clinical characteristics}

Relatively little research has been conducted on sex and cultural differences in BDD. Two groups of investigators have found that women and men were equally likely to meet criteria for BDD (Koran, Abujaoude, Large \& Serpe, 2008; Phillips \& Diaz, 1997). We are aware of no systematic investigation of race and culture in $\mathrm{BDD}$, though the condition has been described in various cultures around the world (Phillips, 1996).

Patients meeting criteria for BDD have been shown to have substantial functional impairment (Phillips, 2000). Negative thoughts about one's appearance interfere with concentration at work and the social lives of patients. In addition, individuals with BDD are so afraid of exposing their flaw to others that they go to great lengths to hide it. They may spend substantial amounts of time camouflaging their perceived defect or avoiding activities in which they will be conspicuous (Phillips, McElroy, Keck, Pope, \& Hudson, 1993). Avoidance of social activities and work is common (Phillips et al., 1993). 
Health care use associated with BDD tends to be directed toward seeking various appearance enhancing medical treatments, especially cosmetic surgery and dermatological procedures. For patients with BDD these treatments typically fail to alleviate distress (Crerand, et al., 2005; Phillips, Grant, Siniscalchi, \& Albertini, 2001). Investigators have found that $48 \%$ to $76 \%$ of patients with BDD sought cosmetic surgery, dermatological treatment, or dental procedures (Crerand, et al., 2005; Phillips, et al., 2001; Veale, Boocock, et al., 1996) and 26\% received multiple procedures (Veale, Boocock, et al., 1996).

Patients meeting criteria for BDD experience an enormous amount of emotional distress and psychiatric co-morbidity (Phillips, Menard, Fay, \& Weisberg, 2005; Veale, Boocock, et al., 1996). Depression and suicidal thoughts are frequent (Gunstad \& Phillips, 2003; Phillips \& Menard, 2006). Also common is social phobia and obsessive compulsive disorder (Gunstad \& Phillips, 2003). Often, compulsions are related to the perceived physical defect, such as checking mirrors or brushing one's hair. Many of these patients also admit to substance, particularly alcohol, use and dependence disorders (Grant, Menard, Pagano, Fay, \& Phillips, 2005; Gunstad \& Phillips, 2003). Co-morbid personality disorders are likely to be present (Phillips \& McElroy, 2000).

Many patients preoccupied with an imagined defect in their physical appearance have such inaccurate perceptions of their appearance that they meet DSM-IV criteria for delusional disorder, somatic type. About $50 \%$ of clinical samples meeting criteria for BDD also meet criteria for delusional disorder, somatic type (Phillips, McElroy, \& Keck, 1994); however, instead of considering this somatic type of delusional disorder a co-morbid condition with $\mathrm{BDD}$, a growing body of research suggests psychotic variants of BDD are simply more severe forms of non-psychotic BDD and are, therefore, best conceived as on the same continuum. It seems that non-psychotic and psychotic BDD share the same demographic characteristics, clinical characteristics, and response to treatment (Phillips, 2004). Further evidence suggests that the cognitions of BDD patients involving such matters as the degree of conviction with which they hold their beliefs are more indicative of a dimensional rather than a categorical structure (Phillips, 2004). Thus, the research data suggest a dimensional model of BDD with varying levels of insight indicating severity of the condition.

\subsection{Cognitive behavioral treatment}

Only two randomized controlled trials have been published on the efficacy of CBT for BDD (Rosen, Reiter, \& Orosan, 1995; Veale, Gournay, et al., 1996). Both interventions involved the restructuring dysfunctional beliefs about one's body and exposure to avoided situations plus response prevention, for example, preventing checking behavior and reassurance seeking. Whereas Rosen et al.'s treatment was administered in eight 2-hour group sessions, Veale et al. administered treatment in 12 weekly individual sessions. Both groups of investigators compared the effects of CBT with those of a waiting list control condition.

Both studies provided strong evidence for the short-term efficacy of CBT for BDD. Rosen et al. found that $81.5 \%$ of treated participants but only $7.4 \%$ of control participants experienced clinically significant improvement, in that their scores on the Body Dysmorphic Disorder Examination (BDDE) dropped more than two standard deviations and they no longer met criteria for BDD. The effect size on the BDDE was substantial $(d=2.81)$ (Rosen et al., 1995). Follow-up assessment, occurring 4.5 months after post- 
treatment, was conducted with only CBT participants, $74 \%$ of whom continued to have achieved clinically meaningful gains (Rosen et al., 1995). Veale et al. reported that at posttreatment $77.8 \%$ of the treatment group either had absent or sub-clinical BDD symptomatology whereas all waiting list participants still met criteria for BDD. Furthermore, Veale's effect size on the BDDE and on a BDD-modified Yale Brown Obsessive Compulsive Scale were also noteworthy ( $d=2.65$ and 1.81, respectively) (Veale, Gournay, et al., 1996). Follow-up was not investigated in this study.

In all, CBT for BDD must be considered an evidence based treatment. Although the potency of the treatments described in these two well-designed controlled trials is noteworthy, a number of questions remain about the efficacy of CBT for BDD. No additional randomized controlled trials have been published. CBT has not been compared with alternative treatments nor with an attention control. It is unclear whether treatment gains reported above could be attributable to nonspecific aspects of therapy. Also, long-term follow-up has not been adequately studied. Other important outcomes, such as physical and social functioning and health care use, have not been assessed. Finally, the generalizability of these findings is unclear. Between the two studies only 36 patients have been treated. Rosen et al.'s sample consisted of women, $83 \%$ of whom had body weight and shape concerns. Veale et al.'s sample specifically excluded potential participants with body weight and shape concerns.

\subsection{Integrating CBT into primary care}

Given that patients with BDD are likely to seek treatment from medical practitioners, treatment should be administered in primary care. Also, primary care physicians are likely to require training in identifying BDD. No published study has assessed an attempt to integrate CBT into primary care.

\section{Future research}

\subsection{Future research on the classification of somatoform disorders}

In the midst of much debate over nosology of the somatoform disorders (Hyler \& Spitzer, 1978; Mayou, Kirmayer, Simon, Kroenke, \& Sharpe, 2005), a number of changes have been proposed for DSM-5 by the DSM-5 Somatic Symptom Disorders Work Group (APA, 2010). As a general framework for these disorders, there is a shift from emphasizing the functionalstatus of somatic symptoms (i.e., that symptoms be medically unexplained) to the dysfunctional thoughts, feelings and behaviors related to somatic symptoms. The mindbody dualism implied by the construct of medically unexplained symptoms as well as the unreliability of assessments of a symptom's true cause (e.g., organic vs. functional) have long been identified as shortcomings (Jablensky, 1999; Mayou et al., 2005). Also, numerous clinician-researchers have expressed concern using pejorative labels (Kirmayer, 1988). In line with these concerns, the terms somatoform, somatization, and hypochondriasis have been eliminated from the most recent proposal for DSM-5 (APA, 2010). The overall category will be renamed, somatic symptom disorders. Detailed below are the most recent proposals for changes to the specific diagnostic categories within somatic symptom disorders group, that is, the creation of diagnostic categories and removal of others. 


\subsubsection{Complex somatic symptom disorder}

A new category, complex somatic symptom disorder, has been proposed to subsume somatization disorder, undifferentiated somatoform disorder, somatoform pain disorder, and most cases of hypochondriasis. The rationale for grouping together these disorders is that their "similarities outweigh their differences" (Dimsdale et al., 2009). As is demonstrated in this chapter, a review of the research from the past 30 years indicates the clinical characteristics of patients meeting criteria for somatization disorder, undifferentiated somatoform disorder, pain disorder, and hypochondriasis (i.e., their presentation of somatic symptoms, incorrect illness attributions, health anxiety, and abnormal illness behavior) are almost identical. In reviewing the epidemiology of somatization disorder and hypochondriasis, Creed and Barksy state there is not sufficient evidence to distinguish between even these two disorders (Creed \& Barsky, 2004). The similarity in treatment response also has been used to argue for a combining of these categories (Dimsdale et al., 2009). In addition, the DSM-5 Somatic Symptom Disorders Work Group cite the research showing physicians see the somatoform disorders as overlapping disorders (Dimsdale, Sharma, \& Sharpe, 2011) as a rationale for uniting somatization disorder, undifferentiated somatoform disorder, pain disorder and hypochondriasis (APA, 2010).

To receive a diagnosis of complex somatic symptom disorder, patients must complain of at least one somatic symptom that is distressing and/or disruptive of their daily lives. Also, patients must have at least two of the following emotional/cognitive/behavioral disturbances: high levels of health anxiety, disproportionate and persistent concerns about the medical seriousness of the symptom(s), and an excessive amount of time and energy devoted to the symptoms and health concerns. Finally, the symptoms and related concerns must have lasted for at least six months.

Future research will examine the epidemiology, clinical characteristics, or treatment of complex somatic symptom disorder as there is no published research on this diagnostic category.

\subsubsection{Simple somatic symptom disorder}

Also new to DSM-5 is the category, simple somatic symptom disorder, which will be used to classify somatically-focused presentations that are more transient and presumably less severe than those meeting criteria for complex somatic symptom disorder. Specifically, simple somatic symptom disorder will be characterized by somatic concerns that have lasted for at least one month and that are accompanied by at least one of the emotional/cognitive/behavioral disturbances listed in the previous section (e.g., health anxiety, concerns about medical seriousness of symptom, or abnormal illness behavior) (APA, 2010). Just as for complex somatic symptom disorder, there is no published research on the epidemiology, clinical characteristics, or treatment of simple somatic symptom disorder.

\subsubsection{IIIness anxiety disorder}

Although the DSM-5 Somatic Symptom Disorders Work Group states that most cases of DSM-IV hypochondriasis are likely to meet criteria for DSM-5 complex somatic symptom 
disorder (APA, 2010), an additional category has been created for patients whose health anxiety is not associated with any somatic symptoms. This new category, illness anxiety disorder, will be characterized by the presentation of no somatic symptoms, or only those mild in severity, and a preoccupation with having or acquiring a serious illness. Also required for the diagnosis are significant health anxiety about having or acquiring a serious illness, excessive behaviors to check one's illness status or maladaptive behaviors to avoid illness concerns, and a persistence of the illness concerns for at least six months (APA, 2010). We are not aware of any published research on the epidemiology, clinical characteristics, or treatment response of patients presenting with this "pure" form illness anxiety.

\subsubsection{Functional neurological disorder}

The proposal for conversion disorder in DSM-5 is to retain the category with slight changes. First, the category will be renamed functional neurological disorder. Second, DSM-IV's requirement that the symptom(s) not be intentionally produced or feigned by the patient will be eliminated, given the difficulty clinicians are likely to have making such a determination. Also no longer required will be the judgment that psychological factors are associated with the symptom(s). Functional neurological disorder is the one somatic symptom disorder category that will retain the dualistic diagnostic criterion of the symptom(s) being medically unexplained. The DSM-5 Somatic Symptom Disorders Work Group cites the recent evidence that neurologists can reliably make the distinction between organic and functional neurological symptoms (Stone, 2009).

\subsubsection{Other disorders}

The current plan for BDD is to move it from the somatic symptom disorders section to the obsessive-compulsive and related disorders section (APA, 2010). The research showing the similarities between the symptomatology and treatment response of BDD and obsessivecompulsive disorder (Castle, Rossell, \& Kyrios, 2006) has been used to justify this change. The diagnostic criteria for DSM-5 BDD now specify that patients need to have performed repetitive behaviors or mental acts in response to appearance concerns at some point during the disorder (APA, 2010).

A new addition to the somatic symptom disorders group will psychological factors affecting medical condition that has resided in the "other conditions" category. This regrouping has been suggested because this condition, whose diagnostic criteria appear to have minimal change from that in DSM-IV, is characterized by the presentation of somatic symptoms and/or distress regarding a medical condition (APA, 2010). Specifically, the DSM-5 criteria include (1) the presence of a general medical condition, (2) psychological or behavioral factors that affect the medical condition. Again, this change is consistent with the attempt to avoid distinguishing between medically explained and unexplained physical symptoms.

\subsection{Future research on cognitive behavioral treatment of somatoform disorders}

One hurdle in administering CBT to somatically-focused patients is that most of these patients seek treatment in primary care, not in psychiatric clinics. When patients with somatoform symptoms are referred to mental health treatment, it is estimated that 50 to $90 \%$ of these patients fail to complete the referral (Escobar, Waitzkin, et al., 1998; Reiger et al., 
1988). Impediments to successful psychiatric referral of patients presenting with somatization occur at both the professional institutional level (e.g., lack of collaboration between primary care and mental health practitioners, lack of mental health training for primary care physicians, inadequate mental health insurance) and level of the individual patient (e.g., concerns about the stigma of having a psychiatric disorder, resistance to psychiatric diagnosis, health beliefs that lead to somatic presentations, pessimism, and fatigue) (Freidl et al., 2007; Pincus, 2003). This literature suggests that the effectiveness of CBT for the somatoform disorders would be enhanced if treatment were conducted in primary care settings where the overwhelming majority of these patients are seen. Also, as suggested by the research on somatization, an integration of mental health providers into primary care and collaboration with primary care physicians and staff would seem imperative in that it could increase the acceptability and availability of CBT. Additional research is required to substantiate these recommendations.

As we move forward to refine the treatment of patients with somatic symptom disorders, one direction for future research is to improve treatment outcome. As a whole, cognitive and behavioral treatments have been shown to reduce physical discomfort, health anxiety, and functional limitations in these patients. Although even the most severely and chronically disturbed somatization and hypochondriacal patients have benefited from treatment, a majority of the treated patients continued to suffer with significant symptomatology after treatment ended (see Woolfolk \& Allen, 2007, for review). Longterm benefits have been demonstrated in only a few trials. Also, there is little data on the impact of treatment on health care utilization, especially when the cost of a psychosocial intervention is factored in to the equation. The investigation of longer-term treatments has been recommended for patients who are severely or chronically disturbed (Woolfolk \& Allen, 2007). Some researchers have argued for studying a stepped-care approach in which all patients would receive low-intensity targeted primary care management. Response to this initial phase of treatment would guide the level of intensity of additional treatment and possible referral to mental health specialists (Arnold et al., 2009; Fink \& Rosendal, 2008).

We have very little data on the mechanisms by which cognitive behavioral treatments have their impact upon somatoform disorders. There are multiple reasons for this. First, the mediators and moderators style of research has not been extensively applied to research on somatoform disorders. Second, the treatments studied have not been disassembled into discrete components and those constituents systematically assessed. Evidence that might shed some light on this issue, that pertaining to differential efficacy of treatment, is also scant. This absence of evidence, to some extent, is the result of much overlap among treatments. When reading the somatoform treatment literature, careful attention must be paid to methods sections, as the labeling of treatments can often be somewhat misleading. Future research could be directed towards examining what components of CBT are most beneficial to somatic symptoms vs. cognitive dysfunctions vs. health anxiety vs. abnormal illness behavior.

\section{Conclusion}

Although the literature on the specific somatoform disorders is relatively small, a few global conclusions can be posited. CBT for somatization, hypochondriasis, and BDD has 
been empirically supported. Specific elements of the cognitive behavioral interventions examined for the different somatoform disorders are outlined in Table 2. There is inadequate data on the treatment of conversion disorder or of pain disorder to make any conclusion.

\begin{tabular}{|l|l|}
\hline Diagnosis & Elements of CBT \\
\hline $\begin{array}{l}\text { Somatization disorder/Undifferentiated } \\
\text { somatoform disorder }\end{array}$ & $\begin{array}{l}\text { Identifying and restructuring cognitions } \\
\text { Altering illness behavior/Behavioral } \\
\text { activation } \\
\text { Relaxation training } \\
\text { Involvement of spouse or family member } \\
\text { Elicitation and expression of emotion }\end{array}$ \\
\hline Hypochondriasis & $\begin{array}{l}\text { Identifying and restructuring cognitions } \\
\text { Exposure plus response prevention }\end{array}$ \\
\hline Conversion Disorder & $\begin{array}{l}\text { Identifying and restructuring cognitions } \\
\text { Altering illness behavior/behavioral } \\
\text { activation } \\
\text { Relaxation training }\end{array}$ \\
\hline Body dysmorphic disorder & $\begin{array}{l}\text { Identifying and restructuring cognitions } \\
\text { Exposure plus response prevention }\end{array}$ \\
\hline Pain disorder & -- \\
\hline
\end{tabular}

Table 2. Specific elements of CBT examined with specific somatoform disorders

An evaluation of the empirical research on CBT for somatoform disorders suggests that in some respects it mirrors the literature on evaluating the efficacy of psychotherapy literature with various mental disorders. CBT has been shown to be superior to various control conditions, especially waiting lists or standard medical treatment. Effect sizes are respectable, relative to other medical or quasi-medical interventions.

There are three clear directions recommended for enhancing the efficacy and effectiveness of CBT for somatoform disorders. The first is to treat patients in the treatment setting where they seek treatment, i.e., primary care settings. Second is to integrate mental health care providers into the primary care treatment setting. And, the third is to increase the length of CBT for patients who are willing to engage in CBT. Two meta-analyses, one on psychosocial treatments of somatization (Kleinstäuber, Witthöft, \& Hiller, 2011), the other on psychosocial treatment of hypochondriasis (Thomson \& Page, 2007), found a positive association between length of treatment and outcome, suggesting longer term treatments may be more potent.

The treatment of somatoform disorders via CBT is very much in its infancy. The methodological quality of the early research has been uneven. Nevertheless, there is sufficient evidence to believe that cognitive behavioral interventions have therapeutic value for a number of the disorders. For somatization, hypochondriasis, and BDD, CBT is the treatment of choice given that no other intervention has demonstrated efficacy. 


\section{References}

Allen, L. A., Escobar, J. I., Lehrer, P. M., Gara, M. A., \& Woolfolk, R. L. (2002). Psychosocial treatments for multiple unexplained physical symptoms: A review of the literature. Psychosomatic Medicine, 64, 939-950.

Allen, L. A., Gara, M. A., Escobar, J. I., Waitzkin, H., \& Cohen-Silver, R. (2001). Somatization: A debilitating syndrome in primary care. Psychosomatics, 42, 63-67.

Allen, L. A., Woolfolk, R. L., Escobar, J. I., Gara, M. A., \& Hamer, R. M. (2006). Cognitivebehavioral therapy for somatization disorder: A randomized controlled trial. Archives of Internal Medicine, 166, 1512-1518.

Altamura, A. C., Carta, M. G., Tacchini, G., Musazzi, A., Pioli, M. R., \& the Italian Collaborative Group on Somatoform Disorders. (1998). Prevalence of somatoform disorders in a psychiatric population: An Italian nationwide survey. European Archives of Psychiatry and Clinical Neuroscience, 248, 267-271.

American Psychiatric Association. (1980). Diagnostic and statistical manual of mental disorders (3rded.). Washington, DC: Author.

American Psychiatric Association. (1987). Diagnostic and statistical manual of mental disorders (3rd ed., rev.). Washington, DC: Author.

American Psychiatric Association. (1994). Diagnostic and statistical manual of mental disorders (4th ed.). Washington, DC: Author.

American Psychiatric Association. (2010). DSM-5 Development. Available at: http://www.dsm5.org/proposedrevision/Pages/SomaticSymptomDisorders.aspx Accessed August 15, 2011.

Arnold, I. A., de Waal, M. W., Eekhof, J. A., Assendelft, W. J., Spinhoven, P., van Hemert, A. M. (2009). Medically unexplained physical symptoms in primary care: A controlled study on the effectiveness of cognitive-behavioral treatment by the family physician. Psychosomatics, 50, 515-524.

Barsky, A. J., \& Ahern, D. K. (2004). Cognitive behavior therapy for hypochondriasis: A randomized controlled trial. Journal of the American Medical Association, 291, 1464-1470.

Barsky, A. J., Fama, J. M., Bailey, E., D., \& Ahern, D. K. (1998). A prospective 4- to 5-year study of DSM-III-hypochondriasis. Archives of General Psychiatry, 55, 737-744.

Barsky, A. J., Orav, E. J., \& Bates, D. W. (2005). Somatization increases medical utilization and cost independent of psychiatric and medical utilization. Archives of General Psychiatry, 62, 903-910.

Barsky, A. J., Wyshak, G., Klerman, G. L., \& Latham, K. S. (1990). The prevalence of hypochondriasis in medical outpatients. Social Psychiatry and Psychiatric Epidemiology, 25, 89-94.

Binzer, M., Andersen, P. M., \& Kullgren, G. (1997). Clinical characteristics of patients with motor disability due to conversion disorder: A prospective control group study. Journal of Neurology Neurosurgery and Psychiatry, 63, 83-88.

Birket-Smith, M., \& Mortensen, E. L. (2002). Pain in somatoform disorders: Is somatoform pain disorder a valid diagnosis? Acta Psychiatrica Scandanavica, 106, 103-108.

Castle, D. J., Rossell, S., \& Kyrois, M. (2006). Body dysmorphic disorder. Psychiatric Clinics of North America, 29, 521-538. 
Chambless, D. L., \& Hollon, S. D. (1998). Defining empirically supported therapies. Journal of Consulting and Clinical Psychology, 66, 7-18.

Clark, D. M., Salkovskis, P. M., Hackmann, A., Wells, A., Fennell, M., Ludgate, J., Ahmad, S., Richards, H. C., \& Gelder, M. (1998). Two psychological treatments for hypochondriasis: A randomised controlled trial. British Journal of Psychiatry, 173, 218-225.

Creed, F., \& Barksy, A. J. (2004). A systematic review of somatisation and hypochondriasis. Journal of Psychosomatic Research, 56, 391-408.

Creed, F., Firth, D., Timol, M., Metcalfe, R., \& Pollock, S. (1990). Somatization and illness behaviour in a neurology ward. Journal of Psychosomatic Research, 34, 427-437.

Crerand, C. E., Phillips, K. A., Menard, W., \& Fay, C. (2005). Nonpsychiatric medical treatment of body dysmorphic disorder. Psychosomatics, 46, 549-555.

Crimlisk, H. L., Bhatia, K., Cope, H., David, A., Marsden, C. D., Ron, M. A. (1998). Slater revisited: 6-year follow-up study of patients with medically unexplained motor symptoms. British Medical Journal, 316, 582-586.

Deveci, A., Taskin, O., Dinc, G., Yilmaz, H., Demet, M. M., Erbay-Dundar, P., Kaya, E., \& Ozmen, E. (2007). Prevalence of pseudoneurological conversion disorder in an urban community in Manisa, Turkey. Social Psychiatry and Psychiatric Epidemiology, 42, 857-864.

Dickinson, W. P., Dickinson, L. M., deGruy, F. V., Main, D. S., Candib, L. M., \& Rost, K. (2003). A randomized clinical trial of a care recommendation letter intervention for somatization in primary care. Annals of Family Medicine, 1, 228-235.

Dimsdale, J., Creed, F. \& the work group. (2009). The proposed diagnosis of somatic symptom disorders in DSM-5 to replace somatoform disorders in DSM-IV: A preliminary report. Journal of Psychosomatic Research, 66, 473-476.

Dimsdale, J., Sharma, N., \& Sharpe, M. (2011). What do physicians think of somatoform disorders. Psychosomatics, 52, 154-159.

Escobar, J. I., Burnam, A., Karno, M., Forsythe, A., \& Golding J. M. (1987). Somatization in the community. Archives of General Psychiatry, 44, 713-718.

Escobar, J. I., Gara, M. I., Diaz-Martinez, A. M., Interian, A., Warman, M., Allen, L. A., Woolfolk, R. L., Jahn, E., Rodgers, D. (2007). Effectiveness of a time-limited cognitive behavior therapy-type intervention among primary care patients with medically unexplained symptoms. Annals of Family Medicine, 5, 328-335.

Escobar, J. I., Gara, M., Waitzkin, H., Silver, R. C., Holman, A., \& Compton, W. (1998). DSMIV hypochondriasis in primary care. General Hospital Psychiatry, 20, 155-159.

Escobar, J. I., Golding, J. M., Hough, R. L., Karno, M., Burnam, M. A., \& Wells, K. B. (1987). Somatization in the community: Relationship to disability and use of services. American Journal of Public Health, 77, 837-840.

Escobar, J. I., Rubio-Stipec, M., Canino, G., \& Karno, M. (1989). Somatic symptom index (SSI): A new and abridged Somatization construct. Prevalence and epidemiological correlates in two large community samples. Journal of Nervous and Mental Disease, 177, 140-146.

Escobar, J. I., Waitzkin, H., Silver, R. C., Gara, M., \& Holman, A. (1998). Abridged somatization: A study in primary care. Psychosomatic Medicine, 60, 466-472. 
Fabrega, H., Mezzich, J., Jacob, R., \& Ulrich, R. (1988). Somatoform disorder in a psychiatric setting: Systematic comparisons with depression and anxiety disorders. Journal of Nervous and Mental Disease, 176, 431-439.

Faravelli, C., Salvatori, S., Galassi, F., Aiazzi, L., Drei, C., \& Cabras, P. (1997). Epidemiology of somatoform disorders: A community survey in Florence. Social Psychiatry and Psychiatric Epidemiology, 32, 24-29.

Fava, G. A., Grandi, S., Rafanelli, C., Fabbri, S., \& Cazzaro, M. (2000). Explanatory therapy in hypochondriasis. Journal of Clinical Psychiatry, 61, 317-322.

Fink, P. (1992). Surgery and medical treatment in persistent somatizing patients. Journal of Psychosomatic Research, 36, 439-447.

Fink, P., \& Rosendal, M. (2008). Recent developments in the understanding and management of functional somatic symptoms in primary care. Current Opinion in Psychiatry, 21, 182-188.

Fink, P., Steen Hansen, M., \& Søndergaard, L. (2005). Somatoform disorders among firsttime referrals to a neurology service. Psychosomatics, 46, 540-548.

Folks, D. G., Ford, C. V., \& Regan, W. M. (1984). Conversion symptoms in a general hospital. Psychosomatics, 25, 285-295.

Freidl, M., Spitzl, S. P., Prause, W., Zimprich, F., Lehner-Baumgartner, E., Baumgartner, C., \& Aigner, M. (2007). The stigma of mental illness: Anticipation and attitudes among patients with epileptic, dissociative or somatoform pain disorder. International Review of Psychiatry, 19, 123-129.

Frohlich, C., Jacobi, F., \& Wittchen, H. U. (2005). DSM-IV pain disorder in the general population. A exploration of the structure and threshold of medically unexplained pain symptoms. European Archives of Psychiatry and Clinical Neuroscience, 256 187-196.

Garcia-Campayo, J., Alda, M., Sobradiel, N., Olivan, B., \& Pascual, A. (2007). Personality disorders in somatization disorder patients: A controlled study in Spain. Journal of Psychosomatic Research, 62, 675-680.

Goldstein, L. H., Chalder, T., Chigwedere, C., Khondoker, M. R., Moriarty, J., Toone, B. K., \& Mellers, J. D. (2010). Cognitive-behavioral therapy for psychogenic nonepileptic seizures: A pilot RCT. Neurology, 74, 1986-1994.

Grabe, H. J., Meyer, C., Hapke, U., Rumpf, H. J., Frevberger, H. J., Diling, H., \& John, U. (2003). Somatoform pain disorder in the general population. Psychotherapy and Psychosomatics, 72, 88-94.

Grant, J. E., Menard, W., Pagano, M. E., Fay, C. \& Phillips, K. A. (2005). Substance use disorders in individuals with body dysmorphic disorder. Journal of Clinical Psychiatry, 66, 309-316.

Greeven A., van Balkom, A. J., Visser, S., Merkelbach, J. W., vanRood, Y. R., van Dyck, R., Van der Does, A. J., Zitman, G. F., \& Spinhoven, P. (2007). Cognitive behavior therapy and paroxetine in the treatment of hypochondriasis: A randomized controlled trial. American Journal of Psychiatry, 164, 91-9.

Gunstad, J. \& Phillips, K. A. (2003). Axis I comorbidity in body dysmorphic disorder. Comprehensive Psychiatry, 44, 270- 276. 
Gureje, O., Simon, G. E., Ustun, T., Goldberg, D. P. (1997). Somatization in cross-cultural perspective: A World Health Organization study in primary care. American Journal of Psychiatry, 154, 989-995.

Gureje, O., Ustun, T. G., \& Simon, G. E. (1997). The syndrome of hypochondriasis: A crossnational study in primary care. Psychological Medicine, 27, 1001-1010.

Hafeiz, H. B. (1980). Hysterical conversion: A prognostic study. British Journal of Psychiatry, 136, 548-551.

Hahn, S. R. (2001). Physical symptoms and physician-experienced difficulty in the physician-patient relationship. Annals of Internal Medicine, 134, 897-904.

Hyler, S. E., \& Spitzer, R. L. (1978). Hysteria aplit asunder. American Journal of Psychiatry, $135,1500-1504$.

Jablensky, A. (1999). The concept of somatoform disorders: A comment on the mind-body problem in psychiatry. In Y. Ono, A. Janca, M. Asai, \& N. Sartorius (Eds.), Somatoform Disorders: A Worldwide Perspective (pp. 3-10). New York: SpringerVerlag.

Jackson, J. L., \& Kroenke, K. (2008). Prevalence, impact, and prognosis of multisomatoform disorder in primary care: A 5- year follow-up study. Psychosomatic Medicine, 70, 430-434.

Katon, W., Lin, E., Von Korff, M., Russo, J., Lipscomb, P., \& Bush, T. (1991). Somatization: A spectrum of severity. American Journal of Psychiatry, 148, 34-40.

Kellner, R. (1983). Prognosis of treated hypochondriasis. Acta Psychiatrica Scandanavica, 67, 69-76.

Kent, D. A., Tomasson, K., Coryell, W. (1995). Course and outcome of conversion and somatization disorder. A four-year follow-up. Psychosomatics, 36, 138-144.

Kirmayer, L. J. (1988). Mind and body as metaphors: Hidden values in biomedicine. In M. J. Lock, D. R. Gordon (Eds.), Biomedicine Examined (pp. 57-93). Boston, MA: Kluwer.

Kirmayer, L. J., \& Robbins, J. M. (1991). Three forms of somatization in primary care: Prevalence, co-occurrence, and sociodemographic characteristics. Journal of Nervous and Mental Disease, 179, 647-655.

Kisely, S., Campbell, L. A., Skerritt, P., \& Yelland, M. J. (2010). Psychological interventions for symptomatic management of non-specific chest pain in patients with normal coronary anatomy. Cochrane Database of Systematic Reviews, 1. CD004101.

Koran, L. M., Abujaoude, E., Large, M.D., \& Serpe, R. T. (2008). The prevalence of body dysmorphic disorder in the United States adult population. CNS Spectrums, 13, 316-322.

Kroenke, K. (2007). Efficacy of treatment for somatoform disorders. A review of randomized controlled trials. Psychosomatic Medicine, 69, 881-889.

Kroenke, K., Sharpe, M., \& Sykes, R. (2007). Revising the classification of somatoform disorders: Key questions and preliminary recommendations. Psychosomatics, 48, 277-285.

Kroenke, K., Spitzer, R. L., deGruy, F. V., Hahn, S. R., Linzer, M., Williams, J. B., Brody, D., \& Davies, M. (1997). Multisomatoform disorder: An alternative to undifferentiated somatoform disorder for the somatizing patient in primary care. Archives of General Psychiatry, 54, 352-358. 
Kröner-Herwig, B. (2009). Chronic pain syndromes and their treatment by psychological interventions. Current Opinion in Psychiatry, 22, 200-204.

Ladee, G. A. (1996). Hypochondriacal Syndromes. Amerstam, The Netherlands: Elsevier.

Larisch, A., Schweickhardt, A., Wirsching, M., \& Fritzsche, K. (2004). Psychosocial interventions for somatizing patients by the general practitioner: A randomized controlled trial. Journal of Psychosomatic Research, 57, 507-514.

Lidbeck, J. (1997). Group therapy for somatization disorders in general practice: Effectiveness of a short cognitive- behavioural treatment model. Acta Psychiatrica Scandinavica, 96, 14-24.

Lin, E. H., Katon, W., Von Korff, M., Bush, T., Lipscomb, R., Russo, J., \& Wagner, E. (1991). Frustrating patients: Physician and patient perspectives among distressed high users of medical services. Journal of General Internal Medicine, 6, 241-246.

Looper, K. J., \& Kirmayer, L. J. (2001). Hypochondriacal conerns in a community population. Psychological Medicine, 31, 577-584.

Katon, W., von Korff, M., Lin, E., Walker, E., Simon, G. E., Bush, T., Robinson, P., \& Russo, J. (1995). Collaborative management to achieve treatment guidelines. Impact on depression in primary care. Journal of the American Medical Association, 273, 1026-1031.

Kleinstäuber, M., Witthöft, M., \& Hiller, W. (2011). Efficacy of short-term psychotherapy for multiple medically unexplained physical symptoms: A meta-analysis. Clinical Psychology Review, 31, 146-160.

Mace, C. J., \& Trimble, M. R. (1996). Ten-year prognosis of conversion disorder. British Journal of Psychiatry, 169, 282-288.

Martin, A., \& Jacobi, F. (2006). Features of hypochondriasis and illness worry in the general population in Germany. Psychosomatic Medicine, 68, 770-777.

Martin, R., Bell, B., Hermann, B., \& Mennemeyer, S. (2003). Non epileptic seizures and their costs: The role of neuropsychology. In G. P. Pritigano \& N. H. Pliskin (Eds.), Clinical Neuropsychology and Cost Outcome Research: A beginning (pp. 235-258). New York: Psychology Press.

Mayou, R., Kirmayer, L. J., Simon, G., Kroenke, K., \& Sharpe, M. (2005). Somatoform disorders: Time for a new approach in DSM-V. American Journal of Psychiatry, $162,847-855$.

Mokleby, K., Blomhoff, S., Malt, U. F., Dahlström, A., Tauböll, E., \& Gjerstad, L. (2002). Psychiatric comorbidity and hostility in patients with psychogenic nonepileptic seizures compared with somatoform disorders and healthy controls. Epilepsia, 43, 193-198.

Morriss, R., Dowrick, C., Salmon, P., Peters, S., Dunn, G., Rogers, A., Lewis, B., CharlesJones, H., Hogg, J., Clifford, R., Rigby, C., \& Gask, L. (2007). Cluster randomised controlled trial of training practices in reattribution for medically unexplained symptoms. British Journal of Psychiatry, 191, 536-542.

Noyes, R., Kathol, R. G., Fisher, M. M., Phillips, B. M., Suelzer, M. T., \& Holt, C. S. (1993).The validity of DSM-III-R hypochondriasis. Archives of General Psychiatry, 50, 961-970. 
Noyes, R., Kathol, R. G., Fisher, M. M., Phillips, B. M., Suelzer, M. T., \& Woodman, C. K. (1994). Psychiatric comorbidity among patients with hypochondriasis. General Hospital Psychiatry, 16, 78-87.

Parsons, T. (1951). Illness and the role of the physician: A sociological perspective. American Journal of Orthopsychiatry, 21, 452-460.

Perkin, G. D. (1989). An analysis of 7,836 successive new outpatient referrals. Journal of Neurology, Neurosurgery, and Psychiatry, 52, 447-448.

Peveler, R., Kilkenny, L., \& Kinmonth A. L. (1997). Medically unexplained physical symptoms in primary care: A comparison of self-report screening questionnaires and clinical opinion. Journal of Psychosomatic Research, 42, 245-252.

Phillips, K. A. (1996). The broken mirror: Understanding and treating body dysmorphic disorder. New York, NY: Oxford University Press.

Phillips, K. A. (2000). Quality of life for patients with body dysmorphic disorder. Journal of Nervous and Mental Disease, 188, 170-175.

Phillips, K. A. (2004). Psychosis in body dysmorphic disorder. Journal of Psychiatric Research, 38, 63-72.

Phillips, K. A., \& Diaz, S. (1997). Gender differences in body dysmorphic disorder. Journal of Nervous and Mental Disease, 185, 570-577.

Phillips, K. A., Grant, J., Siniscalchi, J., \& Albertini, R. S. (2001). Surgical and nonpsychiatric medical treatment of patients with body dysmorphic disorder. Psychosomatics, 42, 504-510.

Phillips, K. A., \& McElroy, S. L. (2000). Personality disorders and traits in patients with body dysmorphic disorder. Comprehensive Psychiatry, 41, 229-236.

Phillips, K. A., McElroy, S. L., \& Keck, P. E. Jr. (1994). A comparison of delusional and nondelusional body dysmorphic disorder in 100 cases. Psychopharmacological Bulletin, 30, 179-186.

Phillips, K. A., McElroy, S. L., Keck, P. E. Jr., Pope, H. G. Jr., \& Hudson, J. I. (1993). Body dysmorphic disorder: 30 cases of imagined ugliness. American Journal of Psychiatry, 150, 302-308.

Phillips, K. A., \& Menard, W. (2006). Suicidality in body dysmorphic disorder: A prospective study. American Journal of Psychiatry, 163, 1280-1282.

Phillips, K. A., Menard, W., Fay, C., \& Weisberg, R. (2005). Demographic characteristics, phenomenology, comorbidity, and family history in 200 individuals with body dysmorphic disorder. Psychosomatics, 46, 317-325.

Phillips, K. A., Pagano, M. E., Menard, W., \& Stout, R. L. (2006). A 12-month follow-up study of the course of body dysmorphic disorder. American Journal of Psychiatry, $163,907-912$.

Pincus, H. A. (2003). The future of behavioral health and primary care: Drowning in the mainstream or left on the bank? Psychosomatics, 44, 1-11.

Reiger, D., Boyd, J., Burke, J., Rae, D. S., Myers, J. K., Kramer, M., Robins, L. N., George, L. K., Karno, M., Locke, B. Z. (1988). One-month prevalence of mental disorders in the US: based on five epidemiological catchment area sites. Archives of General Psychiatry, 45, 977-986. 
Rief, W., Buhlmann, U., Wilhelm, S., Borkenhagen, A., \& Brähler, E. (2006). The prevalence of body dysmorphic disorder: A population-based survey. Psychological Medicine, $36,877-885$.

Rief, W., Hessel, A., Braehler, E. (2001). Somatization symptoms and hypochondriacal features in the general population. Psychosomatic Medicine, 63, 595-602.

Rief, W., Hiller, W., \& Margraf, J. (1998). Cognitive aspects of hypochondriasis and the somatization syndrome. Journal of Abnormal Psychology, 107, 587-595.

Rief, W., Martin, A., Rauh, E., Zech, T., \& Bender, A. (2006). Evaluation of general practitioners' training: How to manage patients with unexplained physical symptoms. Psychosomatics, 47, $304-311$.

Ron, M. (2001). The prognosis of hysteria/somatization disorder. Contemporary approaches to the study of hysteria. Oxford: Oxford University Press.

Robins, L. N., \& Reiger, D. (1991). Psychiatric disorders in America: The epidemiological catchment area study: New York: Free Press.

Rosen, J. C., Reiter, J., \& Orosan, P. (1995). Cognitive-behavioral body image therapy for body dysmorphic disorder. Journal of Consulting and Clinical Psychology, 63, 263 $-269$.

Rosendal, M., Olesen, F., Fink, P., Toft, T., Sokolowski, I., \& Bro, F. (2007). A randomized controlled trial of brief training in the assessment and treatment of somatization in primary care: Effects on patient outcome. General Hospital Psychiatry, 29, 364 -373.

Rost, K. M., Akins, R. N., Brown, F. W., \& Smith, G. R. (1992). The comorbidity of DSM-III-R personality disorders in somatization disorder. General Hospital Psychiatry, 14, 322-326.

Rost, K., Kashner, T. M., \& Smith, G. R. (1994). Effectiveness of psychiatric intervention with somatization disorder patients: Improved outcomes at reduced costs. General Hospital Psychiatry, 16, 381-387.

Sakai, R., Nestoriuc, Y., Nolido, N. V., \& Barsky, A. J. (2010). The prevalence of personality disorders in hypochondriasis. Journal of Clinical Psychiatry, 71, 41-47.

Sar, V., Akyuz, G., Kundakci, T., Kiziltan, E., \& Dogan, O. (2004). Childhood trauma, dissociation, and psychiatric comorbidity in patients with conversion disorder. American Journal of Psychiatry, 161, 2271-2276.

Sarwer, D. B., \& Crerand, C. E. (2008). Body dysmorphic disorder and appearance enhancing medical treatments. Body Image, 5, 50-58.

Simon, G. E., \& VonKorff, M. (1991). Somatization and psychiatric disorder in the NIMH Epidemiologic Catchment Area Study. American Journal of Psychiatry, 148, 14941500.

Smith, G. R., Monson, R. A., Ray, D. C. (1986a). Patients with multiple unexplained symptoms: Their characteristics, functional health, and health care utilization. Archives of Internal Medicine, 146, 69-72.

Smith, G. R., Monson, R. A., \& Ray, D. C. (1986b). Psychiatric consultation letter in somatization disorder. New England Journal of Medicine, 314, 1407-1413.

Smith, G. R., Rost, K., \& Kashner, M. (1995). A trial of the effect of a standardized psychiatric consultation on health outcomes and costs in somatizing patients. Archives of General Psychiatry, 52, 238-243. 
Smith, R. C., Lyles, J. S., Gardiner, J. C., Sirbu, C., Hodges, A., Collins, C., Dwamena, F. C., Lein, C., Given, W. C., Given, B., \& Goddeeris, J. (2006). Primary care clinicians treat patients with medically unexplained symptoms: A randomized controlled trial. Journal of General Internal Medicine, 21, 671-677.

Speckens, A. E. M., van Hemert, A. M., Spinhoven, P., Hawton, K. E., Bolk, J. H., \& Rooijmans, G. M. (1995a). Cognitive behavioural therapy for medically unexplained physical symptoms: A randomised controlled trial. British Medical Journal, 311, 1328-1332.

Stefansson, J. G., Messina, J. A., \& Meyerowitz, S. (1979). Hysterical neurosis, conversion type: Clinical and epidemiological considerations. Acta Psychiatrica Scandanavica, 53, 119-138.

Stone, J., Carson, A., Duncan, R., Coleman, R., Roberts, R., Warlow, C., Hibberd, C., Murray, G., Cull, R., Pelosi, A., Cavanagh, J., Matthews, K., Goldbeck, R., Smyth, R., Walker, J., Macmahon, A. D., \& Sharpe M. (2009). Symptoms 'unexplained by organic disease' in 1144 new neurology out-patients: How often does the diagnosis change at follow-up? Brain, 132, 2878-2888.

Sullivan, M. D. (2000). DSM-IV Pain Disorder: A case against the diagnosis. International Review of Psychiatry, 12, 91-98.

Sumathipala, A., Hewege, S., Hanwella, R., \& Mann, A. H. (2000). Randomized controlled trial of cognitive behaviour therapy for repeated consultations for medically unexplained complaints: A feasibility study in Sri Lanka. Psychological Medicine, 30, 747-757.

Swartz, M., Blazer, D., George, L., \& Landerman, R. (1986). Somatization disorder in a community population. American Journal of Psychiatry, 143, 1403-1408.

Swartz, M., Landermann, R., George, L., Blazer, D., \& Escobar, J. (1991). Somatization. In L. N. Robins \& D. Reiger (Eds.), Psychiatric disorders in America (pp. 220-257). New York: Free Press.

Van der Feltz-Cornelis, C. M., van Oppen, P., Ader, H. J., \& van Dyck, R. (2006). Randomised controlled trial of a collaborative care model with psychiatric consultation for persistent medically unexplained symptoms in general practice. Psychotherapy and Psychosomatics, 75, 282-289.

Veale, D., Boocock, A., Goumay, E., Dryden, W., Shah, R., Willson, R. \& Walburn, J. (1996). Body dysmorphic disorder. A survey of fifty cases. British Journal of Psychiatry, 169, 196-201.

Veale, D., Gournay, K., Dryden, W., Boocock, A., Shah, F., Willson, R., \& Walburn, J. (1996). Body dysmorphic disorder: A cognitive behavioural model and pilot randomised controlled trial. Behaviour Research and Therapy, 34, 717 - 729.

Veith, I. (1965). Hysteria: The History of a Disease. Chicago, IL: University of Chicago Press.

Visser, S., \& Bouman, T. K. (2001). The treatment of hypochondriasis: Exposure plus response prevention vs. cognitive therapy. Behaviour Research and Therapy, 39, 423-442.

Von Korff, M., Gruman, J., Schaefer, J., Curry, S. J., Wagner, E. H. (1997). Collaborative management of chronic illness. Annals of Internal Medicine, 127, 1097-1102. 
Warwick, H. M. C., Clark, D. M., Cobb, A. M., \& Salkovskis, P. M. (1996). A controlled trial of cognitive-behavioural treatment of hypochondriasis. British Journal of Psychiatry, 169, 189-195.

Weissman, M. M., Myers, J. K., \& Harding, P. S. (1978). Psychiatric disorders in a U.S. urban community: 1975-1976. American Journal of Psychiatry, 135, 459-462.

Woolfolk, R. L. \& Allen, L. A. (2007). Treating Somatization: A Cognitive-Behavioral Approach. New York: Guilford Press.

Yutzy, S. H., Cloninger, R., Guze, S. B., Pribor, E. F., Martin, R. L., Kathol, R. G., Smith G. R., \& Strain J. J. (1995). DSM-IV field trial: Testing a new proposal for somatization disorder. American Journal of Psychiatry, 152, 97-101. 


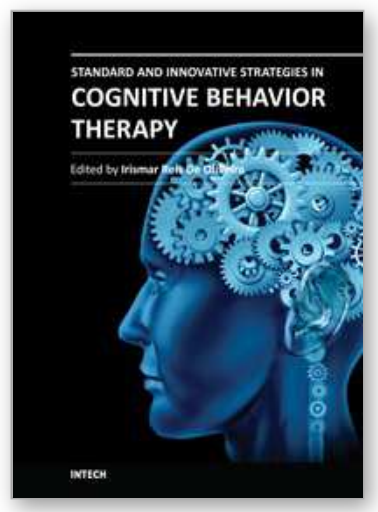

\author{
Standard and Innovative Strategies in Cognitive Behavior Therapy \\ Edited by Dr. Irismar Reis De Oliveira
}

ISBN 978-953-51-0312-7

Hard cover, 190 pages

Publisher InTech

Published online 14, March, 2012

Published in print edition March, 2012

Cognitive-behavioral therapy (CBT) is the fastest growing and the best empirically validated psychotherapeutic approach. Written by international experts, this book intends to bring CBT to as many mental health professionals as possible. Section 1 introduces basic and conceptual aspects. The reader is informed on how to assess and restructure cognitions, focusing on automatic thoughts and underlying assumptions as well as the main techniques developed to modify core beliefs. Section 2 of this book covers the cognitive therapy of some important psychiatric disorders, providing reviews of the recent developments of CBT for depression, bipolar disorder and obsessive-compulsive disorder. It also provides the latest advances in the CBT for somatoform disorders as well as a new learning model of body dysmorphic disorder. Two chapters on addiction close this book, providing a thorough review of the recent phenomenon of Internet addiction and its treatment, concluding with the CBT for substance abuse.

\title{
How to reference
}

In order to correctly reference this scholarly work, feel free to copy and paste the following:

Robert L. Woolfolk and Lesley A. Allen (2012). Cognitive Behavioral Therapy for Somatoform Disorders, Standard and Innovative Strategies in Cognitive Behavior Therapy, Dr. Irismar Reis De Oliveira (Ed.), ISBN: 978-953-51-0312-7, InTech, Available from: http://www.intechopen.com/books/standard-and-innovativestrategies-in-cognitive-behavior-therapy/cognitive-behavioral-therapy-for-somatoform-disorders

\section{INTECH}

open science | open minds

\section{InTech Europe}

University Campus STeP Ri

Slavka Krautzeka 83/A

51000 Rijeka, Croatia

Phone: +385 (51) 770447

Fax: +385 (51) 686166

www.intechopen.com

\section{InTech China}

Unit 405, Office Block, Hotel Equatorial Shanghai

No.65, Yan An Road (West), Shanghai, 200040, China

中国上海市延安西路65号上海国际贵都大饭店办公楼 405 单元

Phone: +86-21-62489820

Fax: $+86-21-62489821$ 
(C) 2012 The Author(s). Licensee IntechOpen. This is an open access article distributed under the terms of the Creative Commons Attribution 3.0 License, which permits unrestricted use, distribution, and reproduction in any medium, provided the original work is properly cited. 